Article

\title{
Potent Anti-HIV Activities and Mechanisms of Action of a Pine Cone Extract from Pinus yunnanensis
}

\author{
Xuan Zhang ${ }^{1,2,3, \dagger}$, Liu-Meng Yang ${ }^{1, \dagger}$, Guang-Ming Liu ${ }^{4}$, Ya-Juan Liu ${ }^{1,3}$, Chang-Bo Zheng ${ }^{5}$, \\ Yong-Jun $\mathrm{Lv}^{4}$, Hao-Zhi $\mathrm{Li}^{4}$ and Yong-Tang Zheng ${ }^{1, *}$
}

1 Key Laboratory of Animal Models and Human Disease Mechanisms of the Chinese Academy of Science \& Yunnan province, Kunming Institute of Zoology, Chinese Academy of Sciences, Kunming 650223, China; E-Mails: snoopykm@126.com (X.Z.); lmyang@mail.kiz.ac.cn (L.-M.Y.); liushui0703@126.com(Y.-J.L.)

2 School of Pharmaceutical Science, Kunming Medical University, Kunming 650500, China

3 Graduate School of the Chinese Academy of Science, Beijing 100039, China

4 School of Pharmacy, Dali University, Dali 671000, China;

E-Mails: 1gm888999@yahoo.com.cn (G.-M.L.); lvyongjun1939@126.com (Y.-J.L.); lihaozhi1943@126.com (H.-Z.L.)

5 School of Pharmacy, China Pharmaceutical University, Nanjing 210009, China;

E-Mail: normalbz@gmail.com

$\dagger$ These authors contributed equally to the work.

* Author to whom correspondence should be addressed; E-Mail: zhengyt@mail.kiz.ac.cn; Tel./Fax: +86-871-519-5684.

Received: 5 April 2012; in revised form: 26 May 2012 / Accepted: 31 May 2012 /

Published: 6 June 2012

Abstract: The anti-HIV activities of a pine cone extract (YNS-PY-F) from Pinus yunnanensis have been evaluated, and its mechanisms of action were also explored. The pine cone extract, YNS-PY-F, potently inhibited HIV-1 ${ }_{\text {IIIB }}$, HIV-1 ${ }_{\mathrm{RF}}, \mathrm{HIV}-1_{\mathrm{A} 17}, \mathrm{HIV}-1_{\mathrm{AO} 18}$ and HIV-2 $2_{\mathrm{ROD}}$ and induced cytopathic effect in C8166 cells with $\mathrm{EC}_{50}$ values of $0.96 \mu \mathrm{g} / \mathrm{mL}, 1.53 \mu \mathrm{g} / \mathrm{mL}$, $0.88 \mu \mathrm{g} / \mathrm{mL}, 7.20 \mu \mathrm{g} / \mathrm{mL}$ and $6.17 \mu \mathrm{g} / \mathrm{mL}$, respectively. The quantification of a $\mathrm{p} 24$ production assay showed that YNS-PY-F significantly inhibited the acute replication of HIV-1 ${ }_{\text {IIIB }}, \mathrm{HIV}-1_{\mathrm{RF}}, \mathrm{HIV}-1_{\mathrm{A} 17}$ and HIV-1 ${ }_{\mathrm{AO} 18}$ in C8166 cells. An MTT assay showed that YNS-PY-F also significantly inhibited the HIV-1 ${ }_{\text {IIIB }}$ induced cytolysis in MT-4 cells with an $\mathrm{EC}_{50}$ value of $2.22 \mu \mathrm{g} / \mathrm{mL}$. The mechanism assays showed that YNS-PY-F had potent inhibitory effects on the fusion between infected cells and uninfected cells, and the activity 
of HIV-1 reverse transcriptase, with $\mathrm{EC}_{50}$ values of $7.60 \mu \mathrm{g} / \mathrm{mL}$ and $4.60 \mu \mathrm{g} / \mathrm{mL}$, respectively. Overall, these data suggest that the pine cone extract from Pinus yunnanensis has potent inhibitory activities against $\mathrm{HIV}-1_{\mathrm{IIIB}}, \mathrm{HIV}-1_{\mathrm{RF}}$, RT inhibitor-resistant strains HIV $-1_{\mathrm{A} 17}$ and HIV-1 $1_{\mathrm{AO} 18}$, and HIV-2 $2_{\mathrm{ROD}}$, and its anti-HIV mechanisms include inhibition of HIV entry and inhibition of reverse transcriptase activity.

Keywords: Pinus yunnanensis; pine cone; anti-HIV activity; reverse transcriptase; fusion

\section{Introduction}

Human immunodeficiency virus (HIV) is a lentivirus that causes acquired immunodeficiency syndrome (AIDS). UNAIDS estimated that there were some 34 million people (31.6 million-35.2 million) people living with HIV, including 2.7 million (2.4 million-2.9 million) new infections diagnosed at the end of 2010.

Antiretroviral therapy is still the major strategy for HIV infection. Considerable success has been achieved in the treatment of HIV infection, and more than two-dozen antiretroviral drugs are available targeting several distinct steps in the viral replication cycle. However, drug toxicity, drug resistance, adverse drug-drug interactions, and accompanying poor patient adherence are still the major factors leading to treatment failure [1]. Therefore, the discovery of novel drugs with new mechanisms of action, low toxicity, high activity and well tolerability is still a challenging issue in HIV treatment.

Medicinal plants play an important role in supporting healthcare system in the World. According to the World Health Organization (WHO), 80\% of the rural population in developing countries mainly utilizes locally available medicinal plants for their primary healthcare needs. Nowadays, a large variety of natural products from medicinal plants, such as ribosome inactivating proteins, alkaloids, flavonoids, lignans, polysaccharides and so on, have been found to inhibit unique enzymes and proteins crucial to the life cycle of HIV, including the reverse transcription process, virus entry, the integrase or protease [2-4]. Therefore, screening potential anti-HIV agents from medicinal plants may be a rapid and effective way for drug discovery.

Pines are trees in the genus Pinus, in the family Pinaceae. There are about 115 species of pine, although different authorities accept anywhere between 105 and 125 species. Pine cones of some species of Pinus have been used for many years in the treatment of bronchitis, cough, asthma and other diseases in traditional Chinese medicine. Researchers have found that pine cone extracts or isolates from some species of Pinus in the Pinaceae family have antiviral, antitumor and immunopotentiating activities [5].

The significant anti-HIV activity of the pine cone extracts or isolates from Pinus nigra Arnold, Pinus parvifloria Sieb. et Zucc and Pinus elliottii var. Elliottii show the potential of pine cones as ideal therapeutic agents for the treatment of AIDS [6-9]. Pinus yunnanensis is also a member of the genus Pinus of the Pinaceae family, distributed mainly in the southwest of China [10]. However, there is still no report on whether the pine cone extract from Pinus yunnanensis has anti-HIV activities. In the present study, the anti-HIV activities of a pine cone extract (YNS-PY-F) from Pinus yunnanensis were evaluated, and its mechanisms of action were also explored. 


\section{Results and Discussion}

\subsection{Cytotoxities and Anti-HIV Activities}

Drug efficacy and drug safety are two sides of the same coin, so they should be evaluated simultaneously [11]. In this study, the cytotoxities and anti-HIV activities in vitro were evaluated simultaneously. The cytotoxities against C8166 and MT-4 cells were evaluated by an MTT assay. In order to evaluate the anti-HIV activities of the pine cone extract (YNS-PY-F) from Pinus yunnanensis, cytopathic effect assay (syncytia assay), quantification of p24 production assay and MTT assay were used in this study.

The cytotoxities and anti-HIV activities of YNS-PY-F are summarized in Table 1. The cytotoxity assay showed that YNS-PY-F had low cytotoxities against C8166 and MT-4 cells, with $\mathrm{CC}_{50} \mathrm{~s}$ of $438.73 \mu \mathrm{g} / \mathrm{mL}$ and $922.47 \mu \mathrm{g} / \mathrm{mL}$, respectively (Table 1, Figure 1A). The syncytia assay showed that YNS-PY-F potently inhibited the cytopathic effect induced by different HIV strains, including laboratory-derived virus strains $\mathrm{HIV}-1_{\mathrm{IIIB}}$ and $\mathrm{HIV}-1_{\mathrm{RF}}$, RT nonnucleoside inhibitor-resistant strain HIV $-1_{\mathrm{A} 17}$ and nucleoside inhibitor-resistant strains HIV-1 ${ }_{\mathrm{AO} 18}$, and HIV-2 ${ }_{\mathrm{ROD}}$, with $\mathrm{EC}_{50} \mathrm{~S}$ of $0.96 \mu \mathrm{g} / \mathrm{mL}$, $1.53 \mu \mathrm{g} / \mathrm{mL}, 0.88 \mu \mathrm{g} / \mathrm{mL}, 7.20 \mu \mathrm{g} / \mathrm{mL}$ and $6.17 \mu \mathrm{g} / \mathrm{mL}$, respectively, with selectivity indexes $\left(\mathrm{SI}=\mathrm{CC}_{50} / \mathrm{EC}_{50}\right)$ of 457.01, 286.75, 498.56, 60.93 and 71.11, respectively (Table 1, Figure 1B).

Table 1. Cytotoxities and anti-HIV activities of YNS-PY-F. $\mathrm{CC}_{50}$ is the concentration that inhibits $50 \%$ of cell viability. $\mathrm{EC}_{50}$ is the effective concentration that inhibits $50 \%$ of viral production or enzyme activity.

\begin{tabular}{|c|c|c|c|c|c|c|}
\hline Samples & Cells & HIV strains/enzyme & Assay & $\mathrm{CC}_{50}(\mu \mathrm{g} / \mathrm{mL})$ & $E C_{50}(\mu \mathrm{g} / \mathrm{mL})$ & SI \\
\hline \multirow[t]{12}{*}{ YNS-PY-F } & \multirow[t]{10}{*}{ C8166 } & \multirow[t]{2}{*}{ HIV-1 $1_{\text {IIIB }}$} & $\mathrm{CPE}$ & 438.73 & 0.96 & 457.01 \\
\hline & & & p24 & & 3.98 & 110.23 \\
\hline & & \multirow[t]{2}{*}{$\mathrm{HIV}-1_{\mathrm{RF}}$} & $\mathrm{CPE}$ & & 1.53 & 286.75 \\
\hline & & & p24 & & 9.48 & 46.28 \\
\hline & & \multirow[t]{2}{*}{$\mathrm{HIV}-1_{\mathrm{A} 17}$} & $\mathrm{CPE}$ & & 0.88 & 498.56 \\
\hline & & & p24 & & 4.04 & 108.60 \\
\hline & & \multirow[t]{2}{*}{$\mathrm{HIV}-1_{\mathrm{AO} 18}$} & CPE & & 7.20 & 60.93 \\
\hline & & & p24 & & 9.79 & 44.81 \\
\hline & & HIV-2 ${ }_{\text {ROD }}$ & $\mathrm{CPE}$ & & 6.17 & 71.11 \\
\hline & & H9/HIV-1 IIIB & $\mathrm{CPE}$ & & 7.60 & 57.73 \\
\hline & MT-4 & HIV-1 IIIB & MTT & 922.47 & 2.22 & 415.53 \\
\hline & - & $\mathrm{RT}$ & ELISA & - & 4.60 & - \\
\hline \multirow[t]{8}{*}{$\mathrm{AZT}$} & \multirow[t]{7}{*}{ C8166 } & \multirow[t]{2}{*}{ HIV-1 $1_{\text {IIIB }}$} & CPE & 1120.84 & $1.30^{\mathrm{a}}$ & $862,184.62$ \\
\hline & & & p24 & & $1.94^{\mathrm{a}}$ & $577,752.58$ \\
\hline & & \multirow[t]{2}{*}{$\mathrm{HIV}-1_{\mathrm{RF}}$} & $\mathrm{CPE}$ & & $2.95^{\mathrm{a}}$ & $379,945.76$ \\
\hline & & & p24 & & $6.48^{\mathrm{a}}$ & $172,969.14$ \\
\hline & & \multirow[t]{2}{*}{$\mathrm{HIV}-1_{\mathrm{A} 17}$} & $\mathrm{CPE}$ & & $4.22^{\mathrm{a}}$ & $265,601.90$ \\
\hline & & & p24 & & $4.11^{\mathrm{a}}$ & $272,710.46$ \\
\hline & & HIV-2 ${ }_{\text {ROD }}$ & $\mathrm{CPE}$ & & $3.07^{\mathrm{a}}$ & $365,094.46$ \\
\hline & MT-4 & HIV-1 ${ }_{\text {IIIB }}$ & MTT & 358.50 & $0.85^{\mathrm{a}}$ & $421,764.71$ \\
\hline
\end{tabular}


Table 1. Cont.

\begin{tabular}{lllllll}
\hline Samples & Cells & HIV strains/enzyme & Assay & C $_{\mathbf{5 0}}(\boldsymbol{\mu g} / \mathbf{m L})$ & EC $_{\mathbf{5 0}}(\boldsymbol{\mu g} / \mathbf{m L})$ & SI \\
\hline NVP & C8166 & HIV-1 AO18 $_{1}$ & CPE & - & $61.70^{\mathrm{b}}$ & - \\
& & & p24 & - & $42.11^{\mathrm{b}}$ & - \\
T20 & C8166 & H9/HIV-1 & CPE & - & $14.96^{\mathrm{a}}$ & - \\
PFA & - & RT & ELISA & - & 1.03 & - \\
\hline
\end{tabular}

SI (selective index $)=\mathrm{CC}_{50} / \mathrm{EC}_{50}$. CPE: cytopathic effect. ${ }^{\mathrm{a}}: \mathrm{ng} / \mathrm{mL} .^{\mathrm{b}}: \mathrm{pM}$. The data shown in the table are means of at least two independent experiments.

Figure 1. Cytotoxities and anti-HIV activities of YNS-PY-F. Cytotoxities on C8166 and MT-4 cells were measured by MTT assay (A); Inhibitory activities on HIV-1 ${ }_{\text {IIIB }}, \mathrm{HIV}-1_{\mathrm{RF}}$, HIV-1 $1_{\mathrm{A} 17}, \mathrm{HIV}-1_{\mathrm{AO} 18}$ and HIV-2 ${ }_{\mathrm{ROD}}$ in C8166 cells were measured by syncytia reduction assay (B); Inhibitory activities on acute replication of HIV-1 $1_{\mathrm{IIIB}}, \mathrm{HIV}-1_{\mathrm{RF}}, \mathrm{HIV}-1_{\mathrm{A} 17}$ and HIV $-1_{\text {AO18 }}$ in C8166 cells were measured by quantification of $\mathrm{p} 24$ antigen production $(\mathbf{C})$; Inhibitory activity on HIV-1 $1_{\text {IIIB }}$ induced cytolysis in MT-4 cells was measured by MTT assay (D). The data shown in the figure are a representative of at least two independent experiments.
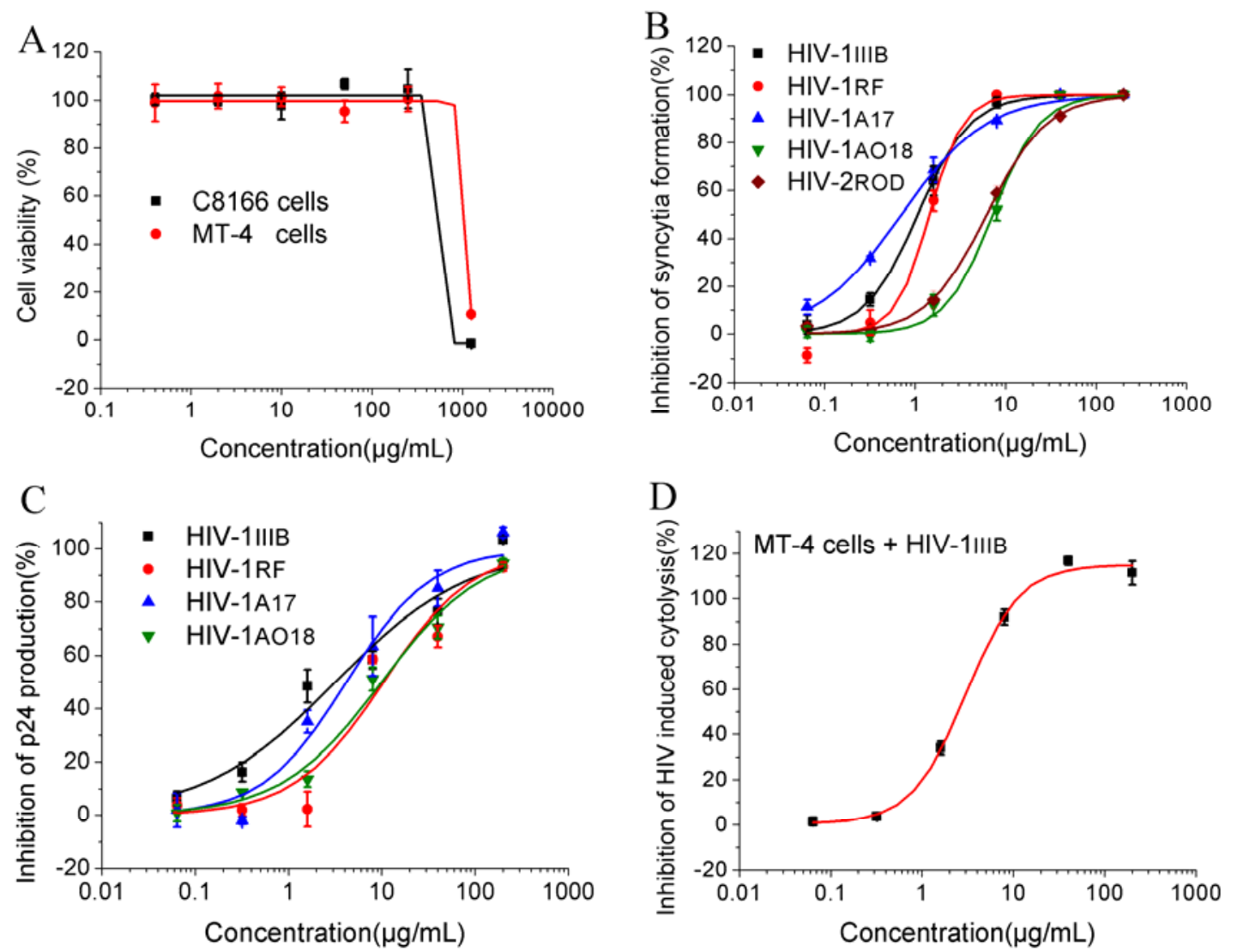

The inhibitory activities of YNS-PY-F on HIV-1 $1_{\mathrm{IIIB}}, \mathrm{HIV}-1_{\mathrm{RF}}, \mathrm{HIV}-1_{\mathrm{A} 17}$ and HIV-1 ${ }_{\mathrm{AO} 18}$ were further confirmed by quantification of p24 antigen production with an ELISA method. Like in the syncytia assay, YNS-PY-F had potent inhibitory activities against p24 antigen production of the four HIV-1 strains in C8166 cells, with $\mathrm{EC}_{50} \mathrm{~s}$ of $3.98 \mu \mathrm{g} / \mathrm{mL}, 9.48 \mu \mathrm{g} / \mathrm{mL}, 4.04 \mu \mathrm{g} / \mathrm{mL}$ and $9.79 \mu \mathrm{g} / \mathrm{mL}$, respectively (Table 1, Figure 1C), suggesting that YNS-PY-F could inhibit the acute replication of these HIV-1 strains in vitro. The inhibitory activities on HIV-1 $1_{\text {IIIB }}$ induced cytolysis in MT-4 cells was also assayed 
by MTT method, the result showed that YNS-PY-F potently inhibited the HIV-1 ${ }_{\text {IIIB }}$ induced cytolysis in MT-4 cells with $\mathrm{EC}_{50}$ values of $2.22 \mu \mathrm{g} / \mathrm{mL}$ and SI of 415.53 (Table 1, Figure 1D), which was much higher than pine cone extracts from Pinus parviflora Sieb et Zucc. and Pinus elliottii var. Elliotti, with SI of 14 and 28, respectively [6].

The results showed that the pine cone extract from Pinus yunnanensis has significant antiviral activities against different $\mathrm{HIV}$ strains with a little different $\mathrm{EC}_{50}$ values. The different $\mathrm{EC}_{50}$ values may result from the different sensitivity of different viral strains to the pine cone extract. Interestingly, the $\mathrm{EC}_{50}$ values of YNS-PY-F against HIV-1 $1_{\mathrm{A} 17}$ was significantly lower than $\mathrm{HIV}-1_{\mathrm{AO} 18}$, suggesting that YNS-PY-F has more potent antiviral activity against HIV-1 $1_{\mathrm{A} 17}$ than $\mathrm{HIV}-1_{\mathrm{AO} 18}$, although the two viral strains are both RT inhibitor-resistant strains. This may be explained by their different mutation sites in the viral RT domain, as different mutation sites can lead to different sensitivity to drugs. $\mathrm{HIV}-1_{\mathrm{A} 17}$ is resistant to nonnucleoside RT inhibitors, while $\mathrm{HIV}-1_{\mathrm{AO} 18}$ is resistant to nucleoside RT inhibitors.

\subsection{Inhibition on HIV-1 Fusion and Activities of Reverse Transcriptase}

Given that YNS-PY-F had potent anti-HIV activities against different HIV strains, its anti-HIV mechanisms were further explored. The HIV entry process, including virus attachment and membrane fusion, is considered as an attractive target for chemotherapeutic intervention, as blocking HIV entry into its target cell leads to suppression of viral infectivity, replication and the cytotoxicity induced by virus-cell contacts [12]. Until now, threre are only two marketed HIV entry inhibitors, the fusion inhibitor enfuvirtide and the CCR5 antagonist maraviroc. HIV-1 reverse transcriptase is a well-known therapeutic target for treating HIV-1 infection and AIDS since there are no human equivalent enzymes and it is essential in HIV-1 infection and disease progression [13]. Although more than ten reverse transcriptase inhibitors have been approved by the U.S. Food and Drug Administration, the discovery of a new generation of HIV RT inhibitors is still urgent because of drug resistance. In the recent two years, a number of interesting, structurally diverse, small-sized compounds were found by virtual screening that may interact with HIV-1 reverse transcriptases [13-15].

Pine cones of different species of Pinus are known to be a rich resource of lignin-carbohydrate complexes (LCCs) and the major ingredient in hot water extracts of pine cones is LCC $[6,8,9]$. LCCs showed one order higher anti-HIV activity than tannins and flavonoids, and the anti-HIV activity induction mechanisms of LCCs include the inhibition of HIV adsorption to and penetration into the cells, and inhibition of reverse transcriptase and protease [16]. Pine cone of Pinus yunnanensis is also abundant in lignin-carbohydrate complexes, and the major component of the hot water extract of pine cone was also lignin-carbohydrate complex (LCC) [17]. Therefore, we further investigated whether YNS-PY-F, a hot water extract from Pinus yunnanensis can inhibit the fusion between normal cells and HIV-1 infected cells, and the activity of recombinant HIV-1 reverse transcriptase. The first fusion inhibitor enfuvirtide (T20) and the reverse transcriptase inhibitor foscarnet sodium (PFA) were used as positive control in fusion assay and reverse transcriptase activity assay, respectively.

As we expected, the cell-to-cell fusion assay results showed that YNS-PY-F potently inhibited the fusion between normal C8166 cells and $\mathrm{H} 9$ cells chronically infected with HIV-1 ${ }_{\text {IIIB }}$ with an $\mathrm{EC}_{50}$ of $7.60 \mu \mathrm{g} / \mathrm{mL}$ (Table 1, Figure 2A), suggesting that YNS-PY-F can inhibit HIV entry into the cells. The 
inhibition of recombinant HIV-1 reverse transcriptase activity was also detected by ELISA method using a commercial kit, the result showed that YNS-PY-F also significantly inhibited HIV-1 reverse transcriptase activity with an $\mathrm{EC}_{50}$ of $4.60 \mu \mathrm{g} / \mathrm{mL}$ (Table 1, Figure 2B), suggesting that it can be a potential reverse transcriptase inhibitor.

Figure 2. Inhibitory effects of YNS-PY-F on cell-to-cell fusion and RT activity. Inhibitory activity on the fusion of uninfected C8166 cells and H9 cells chronically infected HIV-1 $1_{\text {IIIB }}$ was measured by syncytia reduction assay (A); Inhibitory activity on recombinant HIV-1 reverse transcriptase was measured by ELISA assay (B). The data shown in the figure are a representative of at least two independent experiments.
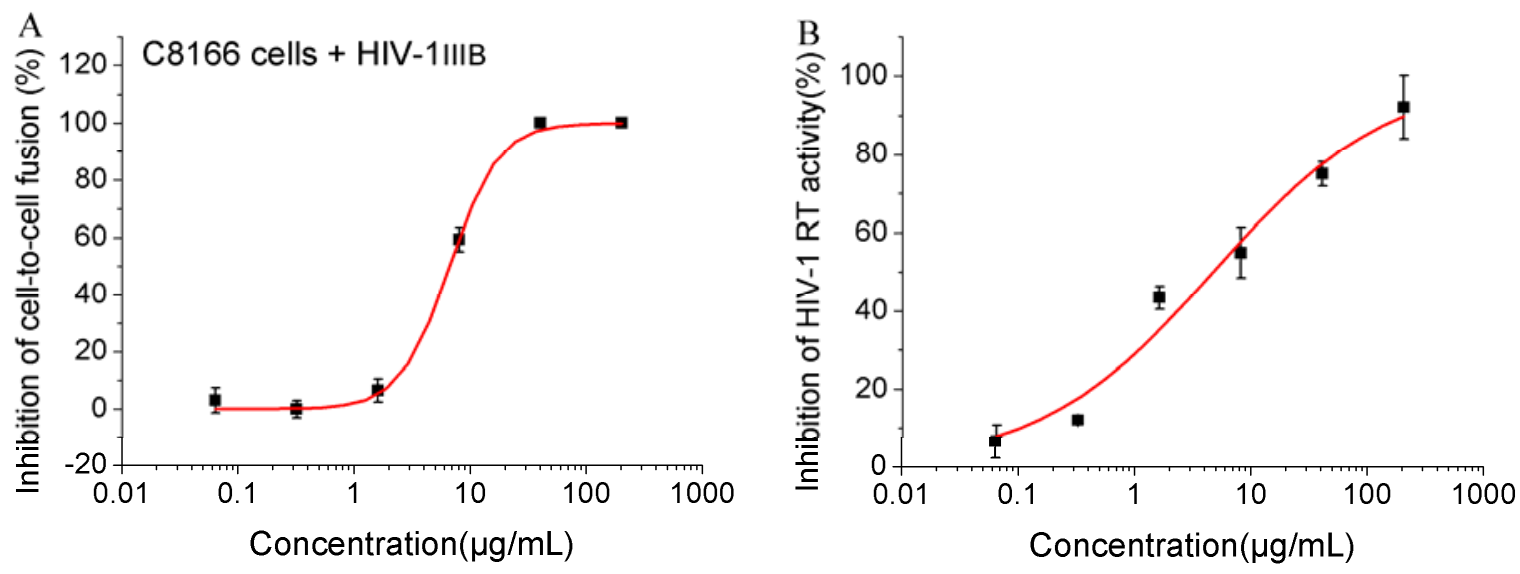

This extract showed both entry- and RT-inhibiting activity. However, it does not indicate that there exist multiple active compounds, as the major component was lignin-carbohydrate complex, and previous reports have proved that the mechanism of anti-HIV activity of LCC includes the inhibition of HIV adsorption to and penetration into the cells, and inhibition of reverse transcriptase [16]. Our results were consistent with the previous report.

Lignin-carbohydrate complexes have diverse pharmacological properties, such as antitumor, anti-microbial, antiparasite, antiviral and immunopotentiation actitity [16]. As the the major component of the pine cone extract was lignin-carbohydrate complex, so besides anti-HIV activity, the extract may have other various pharmacological properties. The potent anti-HIV activities and low cytotoxity in vitro indicate that the pine cone extract from Pinus yunnanensis has the potential to become an alternative medicine for HIV infection, however, its anti-HIV activities in vivo should be further evaluated.

\subsection{Effect on HIV-1 Integrase Nuclear Translocation}

Establishment of stable HIV-1 infection requires the efficient integration of the retroviral genome into the host DNA [18]. The integration event is mediated by the viral enzyme integrase (IN) [19,20]. IN bears a nuclear localization signal (NLS) domain located between residues 161 and 173. After reverse transcription, IN translocates to the nucleus in the form of a compact and stable preintegration complex (PIC), containing the viral reverse-transcribed genome and a number of virion-derived and cellular proteins, such as MA, Vpr and LEDGF/p75 [21]. The PIC nuclear import has been suggested 
to be mediated by the HIV-1 IN, via either the importin alpha or transportin 3 (TNPO3/transportin-SR2) pathways [22]. Therefore, HIV-1 IN nuclear translocation plays an important role in the life cycle of HIV-1 replication. Inhibition of IN nuclear translocation may lead to the failure of viral replication. A peptide bearing this sequence -NLS-IN peptide-inhibited nuclear accumulation of IN in transfected cell-cycle arrested cells [23]. D77, one benzoic acid derivative, has also been reported to inhibit IN nuclear translocation by disrupting the interaction between IN and LEDGF/p75 [24].

To investigate whether YNS-PY-F has inhibitory effect on the HIV-1 IN nuclear translocation, a cell based imaging screening method was used, and D77 was used as a positive control in this assay. However, the result showed that YNS-PY-F had no effect on HIV-1 integrase nuclear translocation even at $200 \mu \mathrm{g} / \mathrm{mL}$. Similar to the negative control (cells treated with no drugs) (Figure 3A), EGFP-IN was mainly localized in nucleus of the HeLa cells treated with YNS-PY-F at $200 \mu \mathrm{g} / \mathrm{mL}$ (Figure 3C), while EGFP-IN was mainly localized in cytoplasm of cells treated with the positive control, D77 at $100 \mu \mathrm{g} / \mathrm{mL}$ (Figure 3B).

Figure 3. Effect of YNS-PY-F on the nuclear import of HIV-1 integrase in HeLa cells. (A) Negative control: EGFP-IN mainly distributed in the nucleus of HeLa cells; (B) D77 at $100 \mu \mathrm{g} / \mathrm{mL}$ : EGFP-IN mainly distributed in the cytoplasm of HeLa cells; (C) YNS-PY-F at $200 \mu \mathrm{g} / \mathrm{mL}$ : EGFP-IN mainly distributed in the nucleus of HeLa cells. The scale bar was $25 \mu \mathrm{m}$.
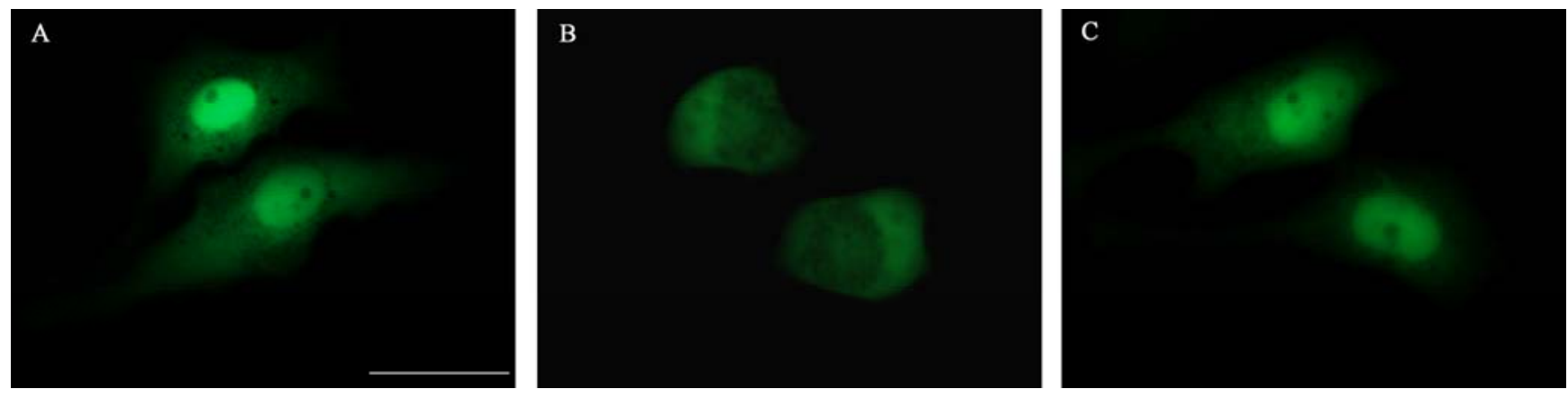

\subsection{Effect on SDF-1 $\alpha$ Induced CXCR4 Internalization}

The chemokine receptors CXCR4 and CCR5, expressing respectively on human $\mathrm{T}$ cells and macrophages, are the two major coreceptors for HIV entry. Numerous efforts have been made to develop a new class of anti-HIV agents that target these coreceptors as an additional or alternative therapy to standard HAART [25]. There are two kinds of HIV entry inhibitors at present: CCR5 antagonists and HIV fusion inhibitors. Although many CXCR4 antagonists have also been studied, they are still at preclinical stages or have been suspended during development. Therefore, research of novel HIV entry inhibitors focuses on CXCR4 antagonists and attachment process inhibitors.

Given that YNS-PY-F potently inhibit the fusion of uninfected C8166 cells and H9 cells chronically infected HIV-1 $1_{\text {IIIB, }}$, and the cell lines used in anti-HIV activities tests were $\mathrm{T}$ cell lines, we further investigated its effect on CXCR4 by a cell based fluorescence imaging assay. SDF-1 and CXCR4 are believed to be a relatively "monogamous" ligand-receptor pair [26], therefore we used SDF-1 $\alpha$ to induce CXCR4 internalization. 
EGFP-CXCR4 was transported to cytoplasm of $293 \mathrm{~T}$ cells after incubated with SDF-1 $\alpha$, a natural ligand of CXCR4 (Figure 4A), the positive compound AMD3100 significantly blocked SDF-1 $\alpha$ induced CXCR4 internalization, EGFP-CXCR4 still distributed mainly in the membranes of 293T cells (Figure 4B), while EGFP-CXCR4 distributed mainly in cytoplasm of 293T cells treated with YNS-PY-F at $200 \mu \mathrm{g} / \mathrm{mL}$ (Figure 4C). The result showed that YNS-PY-F can not inhibit SDF-1 $\alpha$ induced CXCR4 internalization, suggesting it can not be as a CXCR4 antagonist.

Figure 4. Effect of YNS-PY-F on SDF-1 $\alpha$ induced CXCR4 internalization. (A) Negative control: EGFP-CXCR4 mainly distributed in the cytoplasm of $293 \mathrm{~T}$ cells treated by SDF-1 $\alpha$; (B) AMD3100 at $10 \mu \mathrm{M}$ : EGFP-CXCR4 still mainly distributed in the cell membrane of cells treated by SDF-1 $\alpha$ and AMD3100; (C) YNS-PY-F at $200 \mu \mathrm{g} / \mathrm{mL}$ : EGFP-CXCR4 mainly distributed in the cytoplasm of 293 T cells treated by SDF-1 $\alpha$ and YNS-PY-F. The scale bar was $25 \mu \mathrm{m}$.
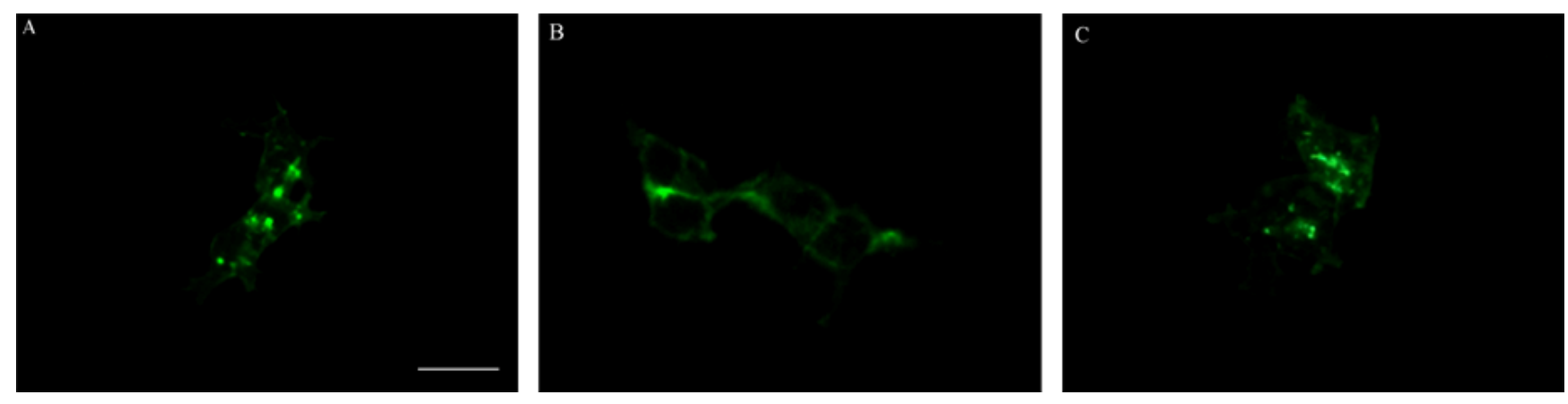

\section{Experimental}

\subsection{Plant Materials and Extraction Procedure}

The air-dried pine cones of Pinus yunnanensis were collected in Yangbi County, Dali Prefecture of Yunnan Province, China, in April 2009. The plant material was identified by Xiao-Kuang Ma (School of Pharmacy, Dali University, Dali, China). A voucher specimen (BBP2010012PY) was deposited in School of Pharmacy, Dali University. The air-dried and powdered pine cones of Pinus yunnanensis $(10.0 \mathrm{~kg})$ were soaked in $95 \%$ ethanol solution $(25 \mathrm{~L})$ for 24 hours for three cycles, and then were filtered. The residues were extracted by boiling water for 2 hours for three cycles and then were extracted by $1 \% \mathrm{NaOH}$ at room temperature, and finally filtered. The filtrate was adjusted to acidity by acetic acid, and then was filtered. The filtrate was precipitated by a threefold amount of ethanol solution, filtered, the filtrate was further precipitated by a fivefold amount of ethanol solution, and filtered, the sediments were washed sequentially with dehydrated ethanol and ethyl ether, then were evaporated under reduced pressure at $40{ }^{\circ} \mathrm{C}$, finally $2.06 \mathrm{~g}$ of extract was obtained and coded as YNS-PY-F. The major ingredient in the hot water extract of pine cones from cones of Pinus yunnanensis was lignin-carbohydrate complex (LCC) [17].The structure of lignin-carbohydrate complex is shown in Figure 5. 
Figure 5. The structure of lignin-carbohydrate complex [16]. Carbohydrate represents polysaccharide portion of lignin-carbohydrate complex.

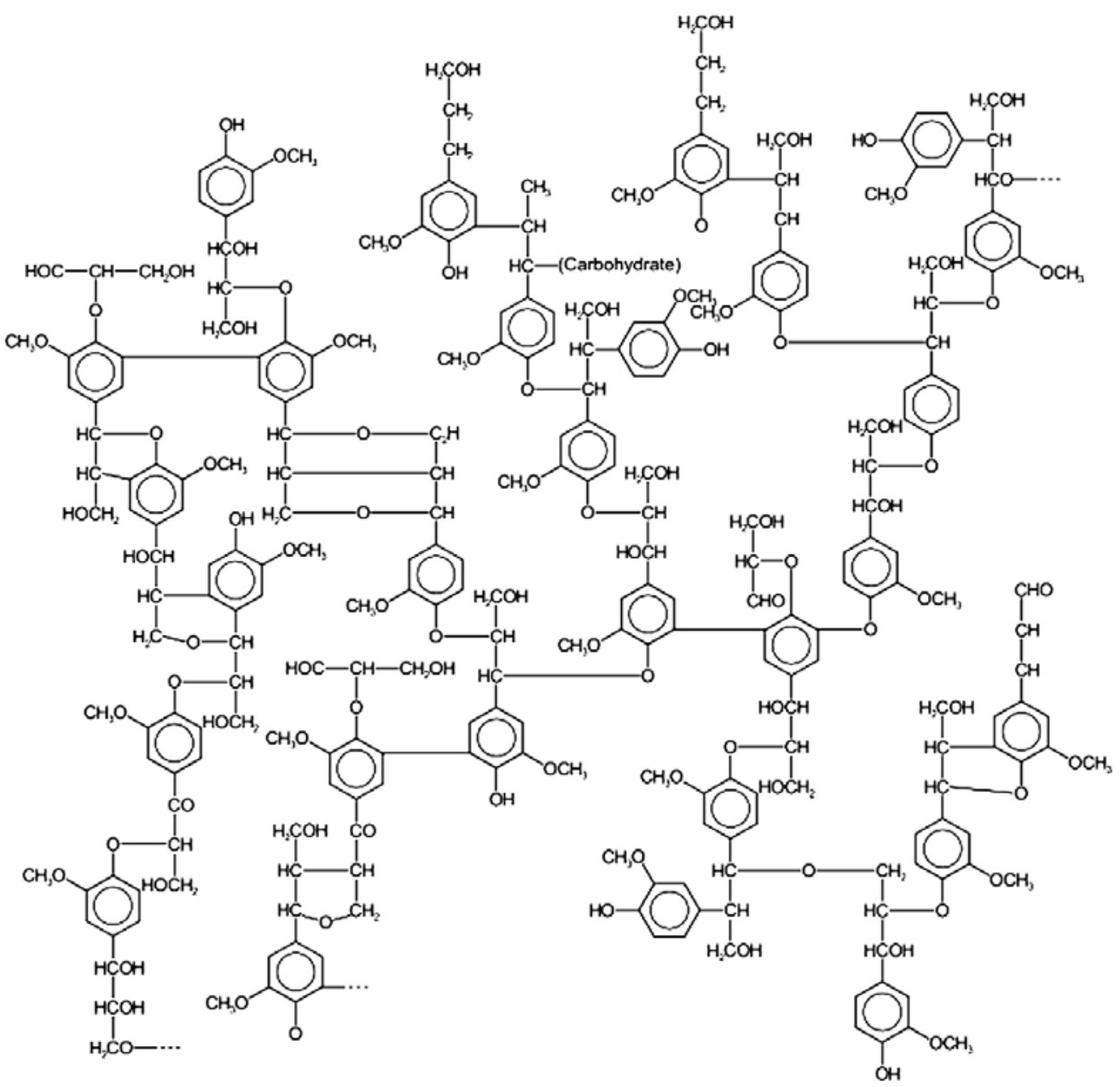

\subsection{Reagents and Chemicals}

MTT, AZT (3'-azido-3'-deoxythymidine) and AMD3100 were purchased from Sigma. Horseradish peroxidase (HRP) labeled goat anti-human IgG was purchased from Dingguo Biotechnology Company (Beijing, China). SDF-1 $\alpha$ was purchased from R \& D Systems (Minneapolis, MN, USA). The p5F1 and monoclonal antibody (McAb) against HIV-1 p24 were prepared by our laboratory [27]. Enfuvirtide (T20) and Reverse Transcriptase Assay kit were purchased from Roche (Basel, Switzerland). Nevirapine (NVP) was purchased from ChemPacific (Baltimore, MD, USA). D77 was kindly donated by Shen Xu (Shanghai Institute of Materia Medica, Chinese Academy of Sciences, Shanghai, China).

\subsection{Plasmid, Cells and Viruses}

The pTRE2hyg-EGFP-C-IN plasmid and 293T stable cell line expressing CXCR4-GFP were kindly presented by David Chi Cheong (The Chinese University of Hong Kong, Hong Kong, China). Cell lines, including C8166 and MT-4 cells were maintained in Gibco complete RPMI-1640 (with 10\% heat-inactivated FBS). HeLa and 293T cells were maintained in DMEM (with 10\% heat-inactivated FBS). The laboratory-derived virus strains $\mathrm{HIV}-1_{\mathrm{IIIB}}$ and $\mathrm{HIV}-1_{\mathrm{RF}}$, RT nonnucleoside inhibitors 
resistant strain $\mathrm{HIV}-1_{\mathrm{A} 17}$ and nucleoside inhibitors resistant strain $\mathrm{HIV}-1_{\mathrm{AO} 18}$, and $\mathrm{HIV}-2_{\mathrm{ROD}}$ were obtained from the NIH AIDS Research and Reference Reagent Program (USA). The 50\% HIV tissue culture infectious dose $\left(\mathrm{TCID}_{50}\right)$ was determined and calculated according to the method of Reed and Muench. All the viruses were stored in small aliquots at $-70^{\circ} \mathrm{C}$.

\subsection{Cytotoxicity Assay}

MTT was used to assess the cytotoxicity of YNS-PY-F on C8166 cells and MT-4 cells [28]. Briefly, cells were seeded in a 96-well plate $\left(4 \times 10^{4}\right.$ per well) in the absence or presence of various gradient concentrations of YNS-PY-F in triplicate, and then were incubated for 3 days (C8166) or 7 days (MT-4) at $37^{\circ} \mathrm{C}$, in a $5 \% \mathrm{CO}_{2}$-humidified incubator. Then MTT (5 mg/mL in PBS) was added to each well. After incubating for 4 hours, $100 \mu \mathrm{L}$ of $50 \% \mathrm{DMF} / 20 \%$ SDS was added, and the plate was incubated at $37{ }^{\circ} \mathrm{C}$ overnight. AZT was used as a positive control. The plate was read on a Bio-Tek Elx 800 ELISA reader at 595/630 nm. The 50\% cytotoxic concentration $\left(\mathrm{CC}_{50}\right)$ was calculated.

\subsection{Inhibition of YNS-PY-F on HIV Induced Cytopathic Effects (CPE)}

The inhibitory effect of YNS-PY-F on HIV induced cytopathic effect was examined by counting the number of syncytia under an inverted microscope [29]. Briefly, C8166 cells $\left(4 \times 10^{4}\right.$ cells per well), infected with virus HIV-1 $1_{\mathrm{IIIB}}, \mathrm{HIV}-1_{\mathrm{RF}}, \mathrm{HIV}-1_{\mathrm{A} 17}, \mathrm{HIV}-1_{\mathrm{AO} 18}$ and HIV-2 $2_{\mathrm{ROD}}$ at a multiplicity of infection (M.O.I. $=0.15$ ), were seeded on 96-well plate in the absence or presence of various gradient concentrations of YNS-PY-F in triplicate. The final volume per well was $200 \mu \mathrm{L}$. After 3 days of culture, the cytopathic effect (CPE) was measured by counting the number of syncytia. AZT was used as a positive control. $50 \%$ effective concentration $\left(\mathrm{EC}_{50}\right)$ was calculated.

\subsection{Effect on HIV-1 Replication in Acute Infection}

The inhibitory effect of YNS-PY-F on HIV-1 replication in acute infection was further examined by quantification of p24 production by ELISA as previously described [30]. Briefly, C8166 cells were infected with HIV-1 $1_{\mathrm{IIIB}}, \mathrm{HIV}-1_{\mathrm{RF}}$ and HIV-1 $1_{\mathrm{A} 17}$ and HIV-1 $1_{\mathrm{Ao} 18}\left(\right.$ M.O.I. $=0.15$ ) at $37{ }^{\circ} \mathrm{C}$, in a $5 \% \mathrm{CO}_{2}$ humidified incubator for 2 hours to allow for viral adsorption. Cells were washed 3 times with PBS. $100 \mu \mathrm{L}$ of cells $\left(4 \times 10^{4}\right.$ cells $)$ were seeded with $100 \mu \mathrm{L}$ of various gradient concentrations of YNS-PY-F and incubated at $37{ }^{\circ} \mathrm{C}$, in a $5 \% \mathrm{CO}_{2}$-humidified incubator for 4 days. Then, $90 \mu \mathrm{L}$ of supertanants were collected from each well and mixed with $10 \mu \mathrm{L}$ of $5 \%$ Triton X-100. HIV-1 p24 expression was assayed by ELISA. AZT was used as a positive control.

\subsection{Effect on HIV-1 ${ }_{\text {IIIB }}$ Induced Cytolysis in MT-4 Cells}

The inhibition of HIV-1 induced lytic effects in MT-4 cells was described previously [31]. Briefly, uninfected or HIV-1 $1_{\text {IIIB }}$ infected (M.O.I. $\left.=0.15\right)$ MT- 4 cells $\left(4 \times 10^{4}\right.$ cells per well) were seeded in 96-well plates with $100 \mu \mathrm{L}$ of various gradient concentrations of YNS-PY-F. Plates were incubated for 7 days at $37{ }^{\circ} \mathrm{C}$ in a $5 \% \mathrm{CO}_{2}$-humidified incubator. On day 7 , the viability of cells was assessed by MTT as described above. AZT was used as a positive control. 


\subsection{Effect on Cell-To-Cell Fusion}

Cell-to-cell fusion between normal C8166 cells and H9 cells chronically infected with HIV-1 $1_{\text {IIIB }}$ was quantified under an inverted microscope as previously described [32]. Briefly, C8166 cells $\left(3 \times 10^{4}\right)$ were co-cultured with $\mathrm{H} 9$ cells chronically infected with HIV-1 ${ }_{\text {IIIB }}\left(1 \times 10^{4}\right)$ in the presence or absence of YNS-PY-F with various gradient concentrations. After incubation at $37{ }^{\circ} \mathrm{C}$ in a $5 \% \mathrm{CO}_{2}$-humidified incubator for 6 hours, the number of syncytia was counted under an inverted microscope. Enfuvirtide (T20) was used as a positive control.

\subsection{Effect on Recombinant HIV-1 Reverse Transcriptase (RT) Activity}

HIV-1 reverse transcriptase (RT) activity was measured by ELISA RT kit using a commercially available kit (Roche) in accordance with the manufacturer's instruction. Briefly, the recombinant HIV-RT solution, YNS-PY-F diluted in lysis buffer and the reaction mixture were sequentially added to each well in microplate modules, then were incubated for 2 hours at $37^{\circ} \mathrm{C}$. Then anti-DIG-POD solution was added, followed by substrate ABTS. Foscarnet sodium (PFA) was used as a positive control. The absorbance at $405 \mathrm{~nm} / 490 \mathrm{~nm}$ (A405/490) was measured using a microplate reader (ELISA, Bio-Tek ELx 800, Winooski, VT, USA). The resulting signal intensity is directly proportional to the RT activity [33].

\subsection{Effect on HIV-1 Integrase (IN) Nuclear Translocation}

HeLa cells were cultured and maintained in Dulbecco's modified Eagle's medium (DMEM) supplemented with $10 \%$ fetal bovine serum (FBS), $100 \mu \mathrm{g} / \mathrm{mL} \mathrm{G} 418.100 \mathrm{U} / \mathrm{mL}$ of streptomycin-penicillin (Invitrogen) at $37^{\circ} \mathrm{C}$ in a $5 \% \mathrm{CO} 2$ incubator. 24 hours before transfection, HeLa cells $(4 \times 105 /$ well) were seeded onto a clear 24-well plate in DMEM containing 10\% FBS. EGFP-C-IN expression vector was transfected into HeLa cells using Lipofectamine 2000 reagent (Invitrogen, Carlsbad, NM, USA) in accordance with the manufacturer's instructions. The medium was removed 5 hours after transfection. Fresh medium containing pine cone extract solution was added at final concentration of $200 \mu \mathrm{g} / \mathrm{mL}$. 24 hours after transfection, cells were fixed with 4\% paraformaldehyde in PBS at room temperature for 15 minutes. Cell imaging was performed by Leica DMI4000 microscopy. D77 was used as a positive control [24].

\subsection{Effect on SDF-1 $\alpha$ Induced CXCR4 Internalization}

293T stable cell line expressing CXCR4-GFP was cultured and maintained in Dulbecco's Modified Eagle Medium supplemented with 10\% fetal bovine serum (FBS), $25 \mathrm{mM}$ HEPES and 1\% of streptomycin-penicillin. Exponentially growing cells $(1 \times 105$ cells/well $)$ were seeded into a clear 96 well plate and cultured for 24 hours. Then the culture medium was removed and fresh culture medium containing pine cone extract solution was added at final concentration of $200 \mu \mathrm{g} / \mathrm{mL}$. The pine cone extract solution was incubated with cells for 20 minutes, then SDF-1 $\alpha$, the natural ligand of CXCR4, was added at a final concentration of $10 \mathrm{nM}$, and incubated for 40 minutes. Fluorescent imaging was carried out to monitor CXCR4-GFP expression and internalization. Images were collected using Leica DMI4000 fluorescence microscope. AMD3100 was used as a positive control. 


\section{Conclusions}

To our knowledge, our data demonstrated for the first time that a pine cone extract from Pinus yunnanensis has potent inhibitory activities against laboratory-derived virus strains HIV-1 $1_{\text {IIIB }}$ and $\mathrm{HIV}-1_{\mathrm{RF}}$, RT nonnucleoside inhibitors resistant strain $\mathrm{HIV}-1_{\mathrm{A} 17}$ and nucleoside inhibitors resistant strain $\mathrm{HIV}-1_{\mathrm{AO} 18}$, and HIV-2 $\mathrm{ROD}_{\text {, }}$ and the anti-HIV mechanisms include inhibition of HIV entry and inhibition of reverse transcriptase. The potent anti-HIV activities and low cytotoxity in vitro indicate that the pine cone extract from Pinus yunnanensis has the potential to become an alternative medicine for HIV infection, however, its anti-HIV activities and toxicity in vivo should be further evaluated.

\section{Acknowledgments}

This research was supported in part by grants from the Key Scientific and Technological Program of China (2009ZX09501-029; 2012ZX10001-006; 2012ZX10001-007), the 973 program (2009CB522306), and the National Natural Science Foundation of China (No.30860365; No.81102483).

\section{References and Notes}

1. Adamson, C.S.; Freed, E.O. Novel approaches to inhibiting HIV-1 replication. Antiviral Res. 2010, 85, 119-141.

2. Cos, P.; Maes, L.; Vanden Berghe, D.; Hermans, N.; Pieters, L.; Vlietinck, A. Plant substances as anti-HIV agents selected according to their putative mechanism of action. J. Nat. Prod. 2004, 67, 284-293.

3. de Clercq, E. Current lead natural products for the chemotherapy of human immunodeficiency virus (HIV) infection. Med. Res. Rev. 2000, 20, 323-349.

4. Zhang, X.; Huang, N.; Zheng, Y.T. Advances in the study of anti-HIV natural compounds derived from traditional Chinese medicines (in Chinese). Acta Pharm. Sin. 2010, 45, 141-153.

5. Sakagami, H.; Kawazoe, Y.; Komatsu, N.; Simpson, A.; Nonoyama, M.; Konno, K.; Yoshida, T.; Kuroiwa, Y.; Tanuma, S. Antitumor, antiviral and immunopotentiating activities of pine cone extracts: Potential medicinal efficacy of natural and synthetic lignin-related materials (review). Anticancer Res. 1991, 11, 881-888.

6. Lai, P.K.; Donovan, J.; Takayama, H.; Sakagami, H.; Tanaka, A.; Konno, K.; Nonoyama, M. Modification of human immunodeficiency viral replication by pine cone extracts. AIDS Res. Hum. Retroviruses 1990, 6, 205-217.

7. Tamura, Y.; Lai, P.K.; Bradley, W.G.; Konno, K.; Tanaka, A.; Nonoyama, M. A soluble factor induced by an extract from Pinus parviflora Sieb et Zucc can inhibit the replication of human-immunodeficiency-virus in vitro. Proc. Natl. Acad. Sci. USA 1991, 88, 2249-2253.

8. Eberhardt, T.L.; Young, R.A. Assessment of the anti-HIV activity of a pine cone isolate. Planta Med. 1996, 62, 63-65.

9. Satoh, K.; Kihara, T.; Ida, Y.; Sakagami, H.; Koyama, N.; Premanathan, M.; Arakaki, R.; Nakashima, H.; Komatsu, N.; Fujimaki, M.; et al. Radical modulation activity of pine cone extracts of Pinus elliottii var. Elliottii. Anticancer Res. 1999, 19, 357-364. 
10. Li, N.; Fu, L.K. Notes on gymnosperms. 1. Taxonomic treatments of some Chinese conifers. Novon 1997, 7, 261-264.

11. Young, R.C.; Friedman, M.A.; Schilsky, R.L.; Sigal, E.V. Drug safety and drug efficacy: Two sides of the same coin. Clin. Cancer Res. 2007, 13, 2533-2534.

12. Este, J.A. Virus entry as a target for anti-HIV intervention. Curr. Med. Chem. 2003, 10, 1617-1632.

13. Garcia-Sosa, A.T.; Sild, S.; Takkis, K.; Maran, U. Combined approach using ligand efficiency, cross-docking, and antitarget hits for wild-type and drug-resistant Y181C HIV-1 reverse transcriptase. J. Chem. Inf. Model. 2011, 51, 2595-2611.

14. Cichero, E.; Fossa, P. Docking-based 3D-QSAR analyses of pyrazole derivatives as HIV-1 non-nucleoside reverse transcriptase inhibitors. J. Mol. Model. 2012, 18, 1573-1582.

15. Mao, Y.; Li, Y.; Hao, M.; Zhang, S.; Ai, C. Docking, molecular dynamics and quantitative structure-activity relationship studies for HEPTs and DABOs as HIV-1 reverse transcriptase inhibitors. J. Mol. Model. 2012, 18, 2185-2198.

16. Sakagami, H.; Kushida, T.; Oizumi, T.; Nakashima, H.; Makino, T. Distribution of lignin-carbohydrate complex in plant kingdom and its functionality as alternative medicine. Pharmacol. Ther. 2010, 128, 91-105.

17. Zhou, P.; Lin, F.; Liu, J.; Lv, Y.J.; Li, H.Z.; Liu, G.M. Determination of carbohydrate content in lignin-carbohydrate complex from pine cone of Pinus yunnanensis Franch (in Chinese). Lishizhen Med. Mater Med. Res. 2011, 22, 1820-1821.

18. Lesbats, P.; Botbol, Y.; Chevereau, G.; Vaillant, C.; Calmels, C.; Arneodo, A.; Andreola, M.L.; Lavigne, M.; Parissi, V. Functional coupling between HIV-1 Integrase and the SWI/SNF Chromatin remodeling complex for efficient in vitro integration into stable nucleosomes. PLoS Pathog. 2011, 7, e1001280.

19. Esposito, D.; Craigie, R. HIV integrase structure and function. Adv. Virus Res. 1999, 52, 319-333.

20. van Maele, B.; Debyser, Z. HIV-1 integrated: An interplay between HIV-1 integrase, cellular and cellular and viral. AIDS Rev. 2005, 7, 26-43.

21. Maertens, G.; Cherepanov, P.; Pluymers, W.; Busschots, K.; de Clercq, E.; Debyser, Z.; Engelborghs, Y. LEDGF/p75 is essential for nuclear and chromosomal targeting of HIV-1 integrase in human cells. J. Biol. Chem. 2003, 278, 33528-33539.

22. Levin, A.; Hayouka, Z.; Friedler, A.; Loyter, A. Transportin 3 and importin alpha are required for effective nuclear import of HIV-1 integrase in virus-infected cells. Nucleus 2010, 1, 422-431.

23. Levin, A.; Armon-Omer, A.; Rosenbluh, J.; Melamed-Book, N.; Graessmann, A.; Waigmann, E.; Loyter, A. Inhibition of HIV-1 integrase nuclear import and replication by a peptide bearing integrase putative nuclear localization signal. Retrovirology 2009, 6, 112.

24. Du, L.; Chen, J.; Yang, L.M.; Zheng, Y.T.; Tang, Y.; Shen, X.; Jiang, H.L. D77, one benzoic acid derivative, functions as a novel anti-HIV-1 inhibitor targeting the interaction between integrase and cellular LEDGF/p75. Biochem. Biophys. Res. Commun. 2008, 375, 139-144.

25. Murakami, T.; Yamamoto, N. Role of CXCR4 in HIV infection and its potential as a therapeutic target. Future Microbiol. 2010, 5, 1025-1039. 
26. Dong, C.Z.; Tian, S.; Madani, N.; Choi, W.T.; Kumar, S.; Liu, D.; Sodroski, J.G.; Huang, Z.; An, J. Role of CXCR4 internalization in the anti-HIV activity of stromal cell-derived factor-1alpha probed by a novel synthetically and modularly modified-chemokine analog. Exp. Biol. Med. (Maywood) 2011, 236, 1413-1419.

27. Liu, G.J.; Wang, J.P.; Xiao, J.C.; Zhao, Z.W.; Zheng, Y.T. Preparation and characterization of three monoclonal antibodies against HIV-1 p24 capsid protein. Cell. Mol. Immunol. 2007, 4, 203-208.

28. Wang, R.R.; Gu, Q.O.; Yang, L.M.; Chen, J.J.; Li, S.Y.; Zheng, Y.T. Anti-HIV-1 activities of extracts from the medicinal plant Rhus chinensis. J. Ethnopharmacol. 2006, 105, 269-273.

29. Wang, R.R.; Gu, Q.; Wang, Y.H.; Zhang, X.M.; Yang, L.M.; Zhou, J.; Chen, J.J.; Zheng, Y.T. Anti-HIV-1 activities of compounds isolated from the medicinal plant Rhus chinensis. J. Ethnopharmacol. 2008, 117, 249-256.

30. Zhang, X.J.; Yang, G.Y.; Wang, R.R.; Pu, J.X.; Sun, H.D.; Xiao, W.L.; Zheng, Y.T. 7,8-Secolignans from Schisandra wilsoniana and Their anti-HIV-1 activities. Chem. Biodivers. 2010, 7, 2692-2701.

31. Xiao, W.L.; Wang, R.R.; Zhao, W.; Tian, R.R.; Shang, S.Z.; Yang, L.M.; Yang, J.H.; Pu, J.X.; Zheng, Y.T.; Sun, H.D. Anti-HIV-1 activity of lignans from the fruits of Schisandra rubriflora. Arch. Pharm. Res. 2010, 33, 697-701.

32. Wang, Y.H.; Tang, J.G.; Wang, R.R.; Yang, L.M.; Dong, Z.J.; Du, L.; Shen, X.; Liu, J.K.; Zheng, Y.T. Flazinamide, a novel beta-carboline compound with anti-HIV actions. Biochem. Biophys. Res. Commun. 2007, 355, 1091-1095.

33. Wang, Q.; Ding, Z.H.; Liu, J.K.; Zheng, Y.T. Xanthohumol, a novel anti-HIV-1 agent purified from Hops Humulus lupulus. Antiviral Res. 2004, 64, 189-194.

Sample Availability: Samples of the pine cone extract (YNS-PY-F) from Pinus yunnanensis is available from the authors.

(C) 2012 by the authors; licensee MDPI, Basel, Switzerland. This article is an open access article distributed under the terms and conditions of the Creative Commons Attribution license (http://creativecommons.org/licenses/by/3.0/). 